Nevşehir Bilim ve Teknoloji Dergisi TARGíd Özel Sayı 89-95 2016

DOI: 10.17100/nevbiltek.210970

URL: http://dx.doi.org/10.17100/nevbiltek.210970

\title{
İç Anadolu Bölgesinin Tarımda Teknoloji Kullanım Projeksiyonu
}

\author{
Bünyamin Demir ${ }^{1 *}$, Emrah Kuş² \\ ${ }^{1}$ Erciyes Üniversitesi, Seyrani Ziraat Fakültesi, Biyosistem Mühendisliği Bölümü, Kayseri \\ ${ }^{2}$ Iğdır Üniversitesi, Ziraat Fakültesi, Biyosistem Mühendisliği Bölümü, Iğdır \\ Öz
}

Günümüz tarımsal üretiminde temel amaç, artan nüfusun ihtiyaçlarını karşılamak için birim alandan daha fazla ve kaliteli ürün almaktır. Mekanizasyonun yaygınlaşması ile tarım teknikleri ve teknolojileri kolay uygulanır olmuş, toprak işleme, ekim, dikim, gübreleme, kimyasal mücadele, hasat ve harman işlemlerindeki verimliliğe bağlı olarak da ürün kalitesi ve verim artmıştır.

Bu çalışmada İç Anadolu Bölgesinin tarımda teknoloji kullanım projeksiyonunun belirlenmesi amaçlanmıştır. Tarımda kullanılan teknolojinin geçmiş on yıllık üretim ve kullanım miktarları baz alınarak projeksiyon katsayısı hesaplanmıştır. Projeksiyon katsayısının artışı veya azalışı doğrultusunda İç Anadolu Bölgesinin tarımda teknoloji kullanımına ait on yıllık projeksiyonları belirlenmiş ve Türkiye ile karşılaştırılmıştır. Projeksiyon katsayısı, diskli traktör pulluğu için \%3.89, toprak frezesi için \%3.57, traktörle çekilen çayır biçme makinesi için \%6.61, ot tırmığı için \%-2.84, hububat ekim makinesi için \%5.50, üniversal ekim makinesi için \%-2.63, pnömatik ekim makinesi için \%-5.52 ve kimyevi gübre dağıtma makinesi için \%1.79 hesaplanmıştır. Projeksiyon katsayısının pozitif elde edilmesi, mevcut alet ve makine sayısının artmasına, negatif elde edilmesi ise azalmasına neden olmuştur. İç Anadolu Bölgesinin diskli pulluk, traktörle çekilen çayır biçme makinesi ve hububat ekim makinesi için hesap edilen projeksiyon katsayısı, Türkiye için elde edilen değerlere göre yüksek bulunmuştur.

Anahtar Kelimeler: Tarım makineleri, mekanizasyon, projeksiyon.

\section{Projection of Technology Using in Agriculture of Central Anatolia Region}

\begin{abstract}
The main aim of current agricultural production is to provide needs of increasing population by getting higher and qualified production from unit area. Thanks to improvements in mechanization, application of agricultural techniques and technologies has been simpler, and increased efficiency in soil tillage, sowing planting and fertilizing, chemical control, harvest, thus quality of production and yield increased.

The aim of this study is to determinate of technology using projection in Central Anatolia Region. Projection coefficient was calculated by using last ten years production and consumption data of technology used in agriculture. Regarding to increase or decrease of projection coefficient, the projection of Central Anatolia Region were determined for last ten years and compared to Turkey. Projection coefficient were calculated as $3.89 \%$ for disc type tractor plough, $3.57 \%$ for rotary tiller , $6.61 \%$ for tractor drawn mower, $-2.84 \%$ for hay rake, $5.50 \%$ for combined seed drill, $-2.63 \%$ for universal drill, $-5.52 \%$ for pneumatic sowing machine and $1.79 \%$ for fertilizer broadcaster. Positive projection coefficient numbers indicate that an increase in the number of current instrument and machine and decrease in otherwise with negative numbers. The numbers for disc type tractor plough, tractor drawn mower ve combined seed drill were found higher comparing the calculated data of Turkey.
\end{abstract}

Keywords: Agricultural machinery, mechanization, projection.

*e-mail: bunyamindemir@erciyes.edu.tr 
1. Giriş

Bir ülke veya bir bölgedeki kırsal kesimin sosyo-ekonomik gelişim düzeyinin artırılması, tarımsal üretimde yeni ve modern teknolojilerin kullanılmasıyla mümkündür. Tarımsal üretimde insan işgücünün azaltılması, verimliliğin arttırılması, zaman kaybının azaltılması gibi işlemler için tarımsal üretim teknolojilerinin tarımda kullanımının önemli bir yeri vardır [1]. Günümüzde ileri tarım teknolojileri deyince akla toprak ve su kaynaklarının geliştirilmesi ve korunması, sulama, gübreleme, tarımsal savaş, üstün nitelikli tohum kullanımı ve tarımsal mekanizasyon gelmektedir [2 ve 3].

Tarımsal mekanizasyon, tarımsal işlemlerin makine ve enerji kullanımıyla gerçekleştirilmesini ifade etmektedir. Bu yolla daha hızlı ve daha büyük kapasitede üretim mümkün olabilmektedir. Tarımda makine kullanımı, diğer tarım teknolojisi uygulamalarından farklı olarak, verim artışını dolaylı etkilemekte; kırsal kesimde yeni üretim yöntemlerinin uygulanmasını sağlamaktadır. Bu yönüyle diğer teknolojik uygulamaların etkinliğini ve ekonomikliğini artırmakta, çalışma koşullarını iyileştirmektedir. Böylece, uygun teknolojilerin kullanımına olanak sağlayarak belirli büyüklüğe sahip üretim alanlarından daha fazla verimin alınmasına yardımcı olmaktadır [4].

Tarımda teknoloji kullanımı, ülkemizde farklı düzeylerde gelişme ve uygulama göstermektedir. $\mathrm{Bu}$ farklılık her bölgede ve aynı bölgedeki tarımsal işletmelerde de karşımıza çıkabilmektedir. Bu çalışmada İç Anadolu bölgesinin tarımda teknoloji kullanım projeksiyonu belirlenmiş ve Türkiye verileri ile karşılaştırmalar yapılmıştır.

\section{Materyal ve Metot}

Çalışmanın materyalini Türkiye ve İç Anadolu Bölgesi'nin 2004-2013 yıllarına ait Türkiye İstatistik Kurumu tarım makineleri verileri oluşturmuştur [5-14]. Tarım makinelerinin on yıllık üretim ve kullanım miktarları dikkate alınarak, sayılarındaki artış ve azalışların yüzdelik oranları hesaplanmış, bu yüzdelik oranların ortalama katsayıları tespit edilmiştir. Bir önceki yıla ait makine sayısı ile o makine için belirlenen katsayıya bağlı olarak, Türkiye ve İç Anadolu Bölgesi’nde yaygın olarak kullanılan tarım alet ve makinelerinin 2023 yılına kadar olan projeksiyonları hesaplanmıştır. Projeksiyon katsayısının pozitif elde edilmesi, mevcut alet ve makine sayısının artmasını, negatif elde edilmesi ise azalmasını ifade etmektedir [15 ve 16].

\section{Bulgular}

İç Anadolu Bölgesi, kulaklı traktör pulluğunda Türkiye genelinin \%11.2'sine, diskli traktör pulluğunda \%11.3’üne, toprak frezesinde \%4.1’ine, kültivatörde ise \%15.5’ine sahiptir [14].

Kulaklı traktör pulluğu (KTP), diskli traktör pulluğu (DTP), toprak frezesi (TF) ve kültivatöre (K) ait geçmiş on yıllık üretim ve kullanım miktarları, geçmiş yıl değişim oranları ve bu sayılara bağlı olarak hesaplanan projeksiyon katsayıları Tablo 1'de verilmiştir.

Tablo 1'de yıllara bağlı olarak hesaplanan projeksiyon katsayılarında en yüksek değer, toprak frezesinde \%3.53 olarak elde edilmiştir. Bunu ise \%1.74 ile kültivatör izlemiştir. Diskli traktör pulluğu için 2007 ve 2011 yıllarında, bir önceki yıla göre azalışın olması nedeniyle negatif olarak hesaplanan geçmiş yıl değişim oranları, projeksiyon katsayısının azalmasına neden olmuştur. 
Tablo 1. Önemli bazı toprak işleme alet ve makineleri projeksiyonu

\begin{tabular}{|c|c|c|c|c|c|}
\hline \multicolumn{6}{|c|}{ Toprak İşleme Alet ve Makineleri (adet) } \\
\hline \multirow{11}{*}{$\Xi$} & \multirow[b]{2}{*}{2004} & KTP & DTP & TF & $\mathbf{K}$ \\
\hline & & 947.416 & 63.149 & 33.771 & 430.074 \\
\hline & 2005 & 958.228 & 64.965 & 34.895 & 430.981 \\
\hline & 2006 & 983.275 & 66.801 & 36.601 & 443.776 \\
\hline & 2007 & 986.291 & 66.491 & 37.604 & 451.214 \\
\hline & 2008 & 996.013 & 66.933 & 38.937 & 457.711 \\
\hline & 2009 & 1.002 .734 & 67.838 & 40.739 & 466.727 \\
\hline & 2010 & 1.014.188 & 67.954 & 41.685 & 479.972 \\
\hline & 2011 & 1.025 .892 & 67.452 & 42.649 & 488.802 \\
\hline & 2012 & 1.041 .903 & 68.332 & 43.972 & 500.126 \\
\hline & 2013 & 1.045 .122 & 68.773 & 46.716 & 503.786 \\
\hline & 2004-2005 & 1.13 & 2.80 & 3.22 & 0.21 \\
\hline$\Xi$ & 2005-2006 & 2.55 & 2.75 & 4.66 & 2.88 \\
\hline 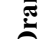 & 2006-2007 & 0.31 & -0.47 & 2.67 & 1.65 \\
\hline$\Xi$ & 2007-2008 & 0.98 & 0.66 & 3.42 & 1.42 \\
\hline 闻 & 2008-2009 & 0.67 & 1.33 & 4.42 & 1.93 \\
\hline $\bar{z}$ & 2009-2010 & 1.13 & 0.17 & 2.27 & 2.76 \\
\hline 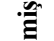 & 2010-2011 & 1.14 & -0.74 & 2.26 & 1.81 \\
\hline تँ & 2011-2012 & 1.54 & 1.29 & 3.01 & 2.26 \\
\hline & 2012-2013 & 0.31 & 0.64 & 5.87 & 0.73 \\
\hline Pro & n Katsayısı (\%) & 1.08 & 0.94 & 3.53 & 1.74 \\
\hline & 2014 & 1.056 .436 & 69.417 & 48.367 & 512.546 \\
\hline & 2015 & 1.067 .872 & 70.067 & 50.076 & 521.459 \\
\hline & 2016 & 1.079 .432 & 70.723 & 51.846 & 530.527 \\
\hline & 2017 & 1.091 .117 & 71.385 & 53.679 & 539.752 \\
\hline 疍 & 2018 & 1.102 .929 & 72.054 & 55.576 & 549.138 \\
\hline 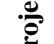 & 2019 & 1.114 .868 & 72.729 & 57.540 & 558.686 \\
\hline & 2020 & 1.126 .937 & 73.410 & 59.574 & 568.401 \\
\hline & 2021 & 1.139 .136 & 74.097 & 61.679 & 578.285 \\
\hline & 2022 & 1.151 .468 & 74.791 & 63.859 & 588.341 \\
\hline & 2023 & 1.163 .933 & 75.491 & 66.116 & 598.572 \\
\hline
\end{tabular}

2013 yılı verilerine göre İç Anadolu Bölgesi traktörle çekilen hububat ekim makinesinde (TÇHEM) Türkiye genelinin \%18.1'ine, kimyevi gübre dağıtma makinesinde (KGDM) \%15.7’sine, üniversal ekim makinesinde (ÜEM) \%1.1'ine, pnömatik ekim makinesinde (PEM) ise \%7.8'ine sahiptir [13]. Bu ekim ve gübreleme makinelerine ait geçmiş on yıllık üretim ve kullanım miktarları, geçmiş yı1 değişim oranları ve bu sayılara bağlı olarak hesaplanan projeksiyon katsayıları da Tablo 2' de verilmiştir.

Tablo 2. Önemli bazı ekim ve gübreleme makineleri projeksiyonu

\begin{tabular}{|c|c|c|c|c|c|}
\hline \multicolumn{7}{|c|}{ Ekim ve Gübreleme Makineleri (adet) } \\
\hline \multirow{3}{*}{$\Xi$} & TÇHEM & KGDM & ÜEM & PEM \\
\cline { 3 - 6 } & 2004 & 13.964 & 51.910 & 825 & 2.329 \\
\cline { 2 - 6 } & 2005 & 17.509 & 53.076 & 627 & 1.020 \\
\cline { 2 - 6 } & 2006 & 18.375 & 55.209 & 610 & 1.345 \\
\hline
\end{tabular}


Demir B., Kuş E.

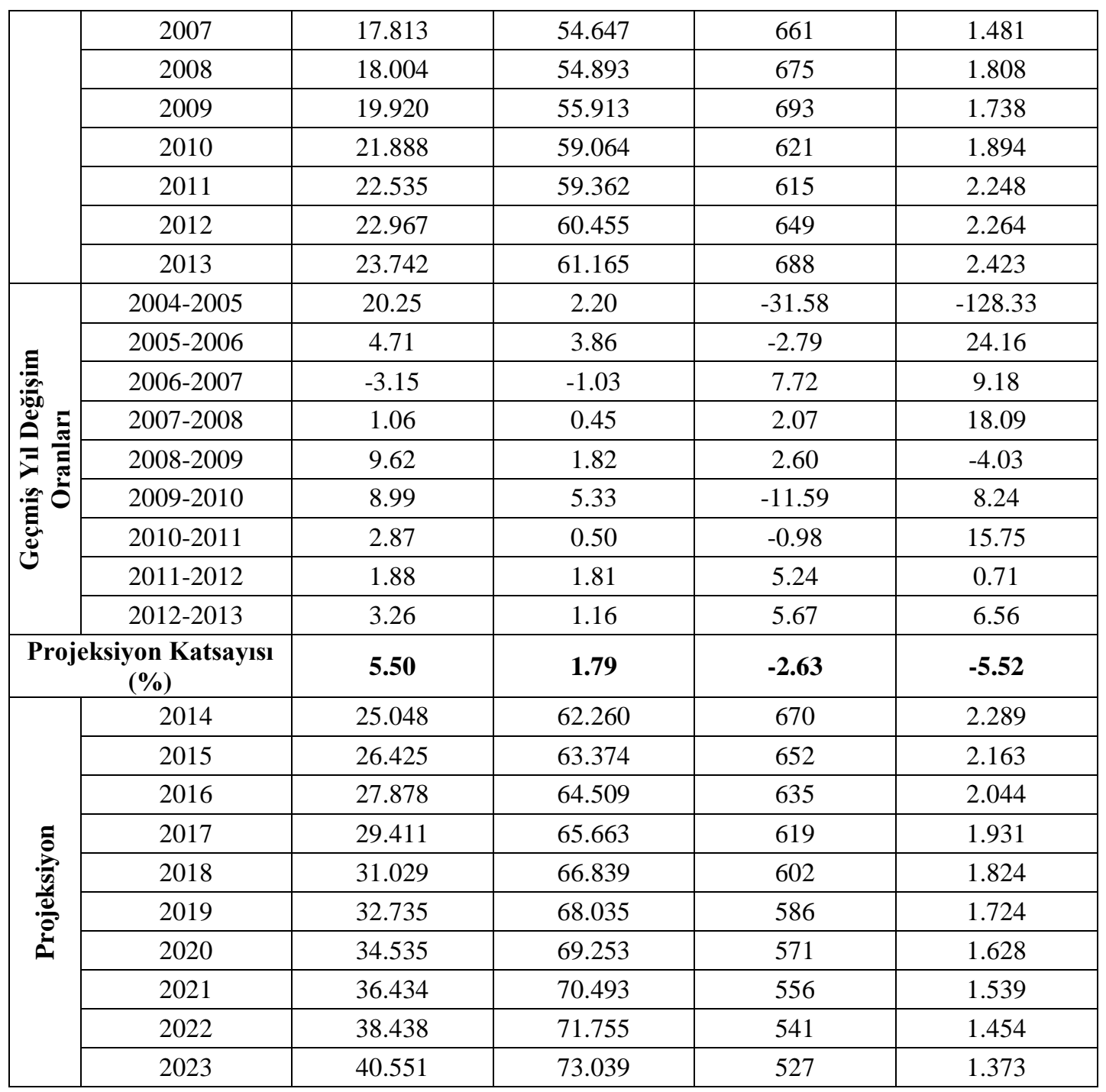

Traktörle çekilen hububat ekim makinesi, 2004 yılında 13.964 adet iken 2013 yılında 23.742 adete ulaşmıştır. Çizelgenin bize verdiği \%5.50 projeksiyon katsayısı ile traktörle çekilen hububat ekim makinesinin 2023 yılında 40.551adete yükseleceğini söylemek mümkündür. Traktörle çekilen hububat ekim makinesinin aksine üniversal ekim makinesi ve pnömatik ekim makinesinin geçmiş yıl değişim oranlarındaki düşüşü de yine çizelgede göze çarpan önemli bir bulgu olup projeksiyon katsayılarının negatif elde edilmesine neden olmuştur. Yıllara göre kimyevi gübre dağıtma makinesine ait \%1.79’u işaret eden projeksiyon katsayısı oranı kimyevi gübre dağıtma makinesi sayısının 2023 yılında 73.039 adete kadar yükselebileceğini öngörmektedir.

Ot tırmığg (OT), biçer bağlar makinesi (BBM), traktörle çekilen çayır biçme makinesi (TÇÇBM) ve sap döver harman makinesine (SDHM) ait geçmiş on yıllık üretim ve kullanım miktarları, geçmiş yıl değişim oranları ve bu sayılara bağlı olarak hesaplanan projeksiyon katsayıları da Tablo 3 'de verilmiştir. 
Tablo 3. Önemli bazı hasat ve harman makineleri projeksiyonu

\begin{tabular}{|c|c|c|c|c|c|}
\hline \multicolumn{6}{|c|}{ Hasat ve Harman Makineleri (adet) } \\
\hline \multirow{11}{*}{$\Xi$} & \multirow[b]{2}{*}{2004} & OT & BBM & TÇÇBM & SDHM \\
\hline & & 5.683 & 209 & 4.115 & 32.808 \\
\hline & 2005 & 5.540 & 204 & 4.334 & 32.382 \\
\hline & 2006 & 5.452 & 287 & 4.884 & 29.896 \\
\hline & 2007 & 5.259 & 312 & 5.763 & 28.909 \\
\hline & 2008 & 5.388 & 326 & 5.869 & 28.632 \\
\hline & 2009 & 5.445 & 343 & 5.883 & 28.041 \\
\hline & 2010 & 5.550 & 304 & 6.287 & 27.683 \\
\hline & 2011 & 4.203 & 327 & 7.016 & 27.411 \\
\hline & 2012 & 4.475 & 318 & 7.297 & 26.624 \\
\hline & 2013 & 4.611 & 352 & 7.697 & 26.534 \\
\hline & 2004-2005 & -2.58 & -2.45 & 5.05 & -1.32 \\
\hline$\Xi$ & 2005-2006 & -1.61 & 28.92 & 11.26 & -8.32 \\
\hline$\overline{\tilde{T}}$ & 2006-2007 & -3.67 & 8.01 & 15.25 & -3.41 \\
\hline$\Xi$ & 2007-2008 & 2.39 & 4.29 & 1.81 & -0.97 \\
\hline 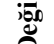 & 2008-2009 & 1.05 & 4.96 & 0.24 & -2.11 \\
\hline$\Xi$ & 2009-2010 & 1.89 & -12.83 & 6.43 & -1.29 \\
\hline 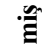 & 2010-2011 & -32.05 & 7.03 & 10.39 & -0.99 \\
\hline$\ddot{\Xi}$ & 2011-2012 & 6.08 & -2.83 & 3.85 & -2.96 \\
\hline & 2012-2013 & 2.95 & 9.66 & 5.20 & -0.34 \\
\hline Pro & n Katsayısı (\%) & -2.84 & 4.97 & 6.61 & -2.41 \\
\hline & 2014 & 4.480 & 370 & 8.206 & 25.894 \\
\hline & 2015 & 4.353 & 388 & 8.748 & 25.270 \\
\hline & 2016 & 4.229 & 407 & 9.326 & 24.661 \\
\hline & 2017 & 4.109 & 427 & 9.942 & 24.066 \\
\hline - & 2018 & 3.993 & 449 & 10.599 & 23.486 \\
\hline$\stackrel{\mathscr{2}}{\varrho}$ & 2019 & 3.879 & 471 & 11.300 & 22.919 \\
\hline & 2020 & 3.769 & 494 & 12.046 & 22.367 \\
\hline & 2021 & 3.662 & 519 & 12.843 & 21.827 \\
\hline & 2022 & 3.558 & 545 & 13.691 & 21.301 \\
\hline & 2023 & 3.457 & 572 & 14.596 & 20.787 \\
\hline
\end{tabular}

Türkiye geneline göre ot tırmığının (OT) \%4.3’ü, biçer bağlar makinesinin (BBM) \%4.2'si, traktörle çekilen çayır biçme makinesinin (TÇÇBM) \%10.5'i, sap döver harman makinesinin (SDHM) ise \%14.6’sı İç Anadolu bölgesinde bulunmaktadır [13].

Tablo 3'de yer alan projeksiyon katsayılarında en yüksek değer, traktörle çekilen çayır biçme makinesinde elde edilmiştir. 2004 yılında 4.115 adet olan traktörle çekilen çayır biçme makinesi kullanımı, 2013 yılında 7.697 adete yükselmiştir. \%6.61 olarak hesaplanan projeksiyon katsayısı ile de 2023 yılında 14.596 olacağı öngörülmektedir. Sap döver harman makinesi sayılarının bir önceki yıla göre sürekli azalışı, değişim oranlarının ve buna bağlı olarak elde edilen projeksiyon katsayısının negatif çıkmasına neden olmuştur. Sap döver harman makinesinde görülen bu durum 2005, 2006, 2007 ve 2011 yıllarında ot tırmığında da karşımıza çıkmıştır. 
Türkiye ve İç Anadolu bölgesi tarım makineleri projeksiyon katsayılarının karşılaştırıldığı Şekil 1'de İç Anadolu bölgesi için hesaplanan diskli pulluğun projeksiyon katsayısı dikkati çeken bir bulgu olmuştur. Sap döver harman makinesi ve üniversal ekim makinesi için elde edilen projeksiyon katsayıları, 2023 yılına kadar hem Türkiye, hem de İç Anadolu bölgesinde bu makinelerin azalacağını öngörmektedir.

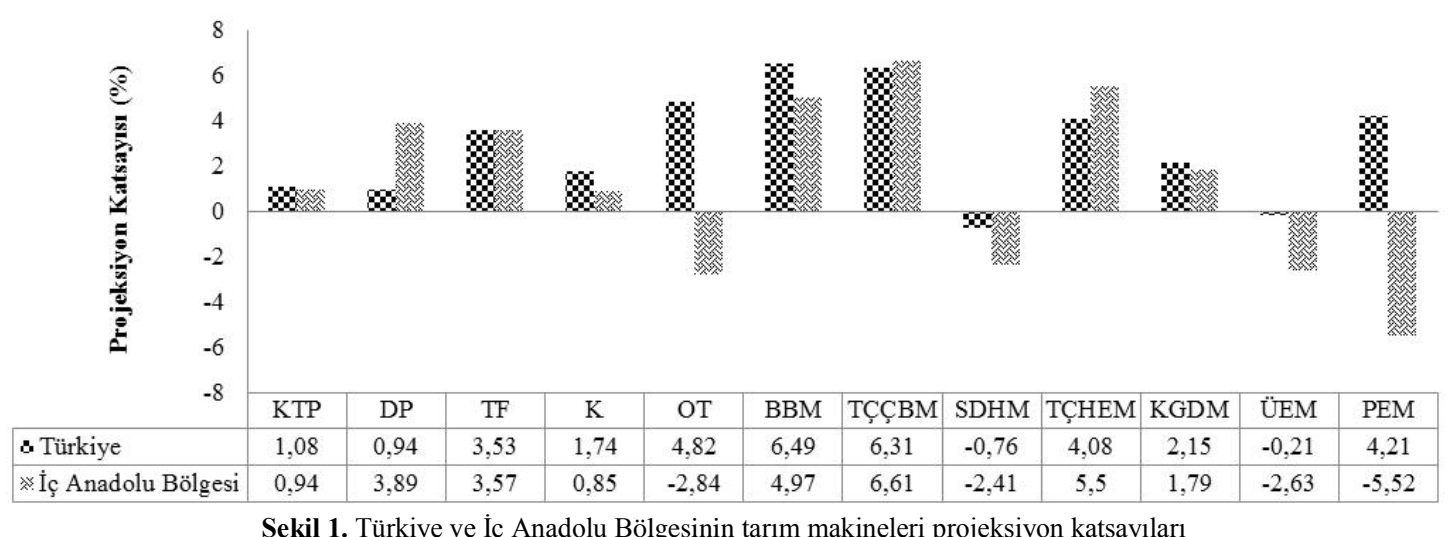

\section{Tartışma ve Sonuç}

Ülkemizde tarımda makine kullanımının başladığı zamandan bu yana, traktör ve traktörle birlikte kullanılan tarım alet ve makineleri varlığında önemli gelişmeler kaydedilse de, Altuntaş ve Demirtola [17] Türkiye'nin mekanizasyon düzeyinin istenilen ölçüde olmadığını belirtmiştir.

Tarımda teknoloji kullanım projeksiyonu değerlerinin düşük elde edilmesi, bölgedeki makine kullanım etkinliğinin az olduğunu da göstermektedir. Tarımsal üretimin arttırılmasında tarım teknolojisi uygulamalarının yaygınlaştırılması ve bilinçli yapılması temel amaç olmalıdır. Gürsoy [18]'a göre tarımsal üretimde karlılığı sağlamak için bölge işletmelerinin yapısına uygun makinelerin seçilmesi ve kullanılması kaçınılmazdır.

Çalışmada Türkiye ve İç Anadolu bölgesinin tarımda teknoloji kullanım projeksiyonunun, ele alınan alet ve makineler için belirlenen projeksiyon katsayılarının pozitif elde edilmesi doğrultusunda 2023 yılına kadar artacağı, projeksiyon katsayısının negatif elde edildiği alet ve makinelerde ise azalma olacağ1 sonucuna varılmıştır.

\section{Kaynaklar}

[1] Gürsoy, S., Sessiz, A., Eliçin, A.K., Akın, S., Esgici, R., “ Diyarbakır İlinin Agro-Ekolojik Alt Bölgelerine Göre Tarımsal Yapı ve Mekanizasyon Özelliklerinin İrdelenmesi ”28. Ulusal Tarımsal Mekanizasyon Kongresi, 4-6 Eylül, 158-167 s, Konya, 2013

[2] Gökdoğan, O., “ Türkiye'nin Tarımsal Mekanizasyon Durumu ” 28. Ulusal Tarımsal Mekanizasyon Kongresi, 4-6 Eylül, 46-50 s, Konya, 2013

[3] Yavuzcan, G., “ Ordu İli ve Yöresinin Tarımsal Mekanizasyon Sorunları ve Çözüm Yolları" Ordu ve Yöresinin Tarımsal ve Sosyo-Ekonomik Sorunları ve Çözüm Yolları Sempozyumu, 3-5 Ağustos, 214-220 s, Ordu, 1983 
[4] Saral, A., Vatandaş, M., Güner, M., Ceylan, M., Yenice, T., “ Türkiye Tarımının Makinalaşma Durumu ” TMMOB Ziraat Odası 5. Teknik Kongresi, 17-21 Ocak, 901-923 s, Ankara, 2000

[5] Anonim, Tarımsal Yapı ve Üretim. T.C. Başbakanlık Türkiye İstatistik Kurumu (TUİK), Ankara, 2004

[6] Anonim, Tarımsal Yapı ve Üretim. T.C. Başbakanlık Türkiye İstatistik Kurumu (TUİK), Ankara, 2005

[7] Anonim, Tarımsal Yapı ve Üretim. T.C. Başbakanlık Türkiye İstatistik Kurumu (TUİK), Ankara, 2006

[8] Anonim, Tarımsal Yapı ve Üretim. T.C. Başbakanlık Türkiye İstatistik Kurumu (TUİK), Ankara, 2007

[9] Anonim, Tarımsal Yapı ve Üretim. T.C. Başbakanlık Türkiye İstatistik Kurumu (TUİK), Ankara, 2008

[10] Anonim, Tarımsal Yapı ve Üretim. T.C. Başbakanlık Türkiye İstatistik Kurumu (TUİK), Ankara, 2009

[11] Anonim, Tarımsal Yapı ve Üretim. T.C. Başbakanlık Türkiye İstatistik Kurumu (TUİK), Ankara, 2010

[12] Anonim, Tarımsal Yapı ve Üretim. T.C. Başbakanlık Türkiye İstatistik Kurumu (TUİK), Ankara, 2011

[13] Anonim, Tarımsal Yapı ve Üretim. T.C. Başbakanlık Türkiye İstatistik Kurumu (TUİK), Ankara, 2012

[14] Anonim, Tarımsal Yapı ve Üretim. T.C. Başbakanlık Türkiye İstatistik Kurumu (TUİK), Ankara, 2013

[15] Anonim, T.C. Mersin Valiliği İl Tarım Müdürlüğü Mersin Tarım Master Planı, Mersin, 2011

[16] Demir, B., “ Mersin İlinin Tarımda Teknoloji Kullanım Projeksiyonu ” Alınteri Zirai Bilimler Dergisi, 24(B), 29-34, 2013

[17] Altuntaş, E., Demirtola, H., “ Ülkemizin Tarımsal Mekanizasyon Düzeyinin Coğrafik Bölgeler Bazında Değerlendirilmesi ” GOÜ. Ziraat Fakültesi Dergisi, 21(2), 63-70, 2004

[18] Gürsoy, S.,“ Güneydoğu Anadolu Bölgesinde Tarımsal Üretimin Gelişmesinde Mekanizasyonun Rolü ” Batman Üniversitesi Yaşam Bilimleri Dergisi, 1(2), 339-346, 2012 